\title{
From Needs and Dilemmas Facing View of Elderly People Living with HIV/AIDS Long-Term Care Measures in Taiwan
}

\author{
Ching-Teng $\mathrm{Yao}^{1}$, Chien-Hsing Tseng ${ }^{2}, \&$ Yu-Ming Chen ${ }^{1}$ \\ ${ }^{1}$ Master Program of Long-Term Care in Aging, Kaohsiung Medical University, Kaohsiung, Taiwan \\ ${ }^{2}$ Department of Adult and Continuing Education, National Chung Cheng University, Chiayi, Taiwan \\ Correspondence: Ching-Teng Yao, College of Nursing, Kaohsiung Medical University, 100, Shih-Chuan 1st Road, \\ Sanmin District, Kaohsiung, 80708, Taiwan. Tel: 886-7-312-1101 ext. 2631. E-mail: angusyao@kmu.edu.tw
}

\author{
Received: July 12, 2017 Accepted: August 30, $2017 \quad$ Online Published: September 28, 2017 \\ doi:10.5539/ass.v13n10p18 URL: https://doi.org/10.5539/ass.v13n10p18
}

\begin{abstract}
The life of people living with HIV has been prolonged with HAART, and since 1997 the introduction of antiretroviral HAART in Taiwan has increased the survival rate of infected people to $85.9 \%$. Therefore, with the extension of the life of people living with HIV and the entry into the old age, how to provide suitable long-term care services is an issue that Taiwan policy needs to face and think. This research through surveys and interviews to find Taiwan elderly people living with HIV in Taiwan needs and plight of the contains (1) diseases and health care issues, (2) social prejudice and discrimination (3) psychology and adjustment of the identity and reflection (4) adjustment of interpersonal relationships. According to the empirical data shows Taiwan's long-term care measures in difficulties arising in the care for older people living with HIV (1) non-suitable for elderly people living with HI community long-term care services; (2) long-term care institution the exclusion of people living with HIV (3) lack of financial resources of older living with HIV with using institutional long term care. (4) the incoherence of HIV medical and long-term care measures. (5) course focuses on long-term care health care, neglect the psychosocial dimensions of older people living with HIV. This study attempts to present long-term care of the elderly people living with HIV needs and challenges and dilemmas facing in Taiwan.
\end{abstract}

Keywords: Needs, Dilemmas facing, People living with HIV/AIDS, Long-term care, Taiwan

\section{Introduction}

\subsection{Introduce the Problem}

According to the statistics of the Taiwan Ministry of Health and Welfare, up to the September 2016 in Taiwan, there are 33,000 people are living with HIV. Due to the effect of life extension of the people living with HIV by the emergence of antiviral drug mixture therapy (HAART), thus make the infected with HIV regarded as a chronic disease (Gorman \& Nelson, 2004). Since the introduction of antiviral drug therapy (HAART) in 1997, the survival rate of infected patients has increased to $85.9 \%$ (Twu, Huang, Lai, Ming, \& Su, 2004). Therefore, with the extension of the lives of infected people and the emergence of elderly infected persons, how to provide appropriate long-term care services for the latter turns out to be a must be issue for the care workers to rethink and consider (Yin \& Li, 2002).

The goal of this research is to understand the needs of elderly people with HIV/AIDS in Taiwan turns out to be a starting point of this research, to know the actual need of long-turn care and the facing difficulties and have a reflective conversation with the current long-term care system (Wu, 2005). With a further knowledge of finding out the shortcomings of this care system, the purpose of this study hopes to be a useful reference of long-term care experience and policy-driven for localized HIV/AIDS infection (Hung, 2008).

\section{Method}

In order to understand the experience of the need and using dilemma of long-term care, this study adopts the qualitative diagram. The data collection and analysis, the design, the steps, the tools and the analysis method are as follows. The interview started from November 2016 to February 2017 and participants were mainly members of the elderly AIDS support group. We obtain the consents of the infected persons individually and family members were included. All of our participants understood the purpose of this study and agreed to be interview. 
After the invitation to participate in the study, the respondents agreed to the recording by the researcher based on an open interview questionnaire, including their knowledge of AIDS infection experience, how to adapt to the long-term care needs and difficulties. Moreover, the impacts on individuals and their families; the suggestions both on the work and policy of the long-term care of HIV/AIDS workers are included, as well. The study conducted individual interviews outside the group meeting for an average of one hour to an AIDS Social Welfare Service Institution. The interview process, with the consent of the interviewees, conducts the entire recording and process record, and the contents of the recording will be verbatim. If the interview recording failed, process records will use as assisted and analyzed.

The process of data analysis is included five steps: description, organization, link, confirm / legalization and reproduction report. The results of this analysis will aggregate by the cross-case study and build up the context of the phenomenon. Then, researcher synthesizes all the interview and records of interviews. When finished reading the data, researcher discusses the main concepts, divides them in words or behavior, divide the narratives into small units, and then give them an idea according to the nature of the small units. The conceptual formation of common concepts, and the constant comparison, the correlation between the data and data; and then summed up the higher core of the category which is according to its meaning to be named. Finally, return to the original word or record, to classified, compared and illustrated by examples. The results is divided into two large range items according to the research purpose: the long-term care needs of elderly people with long-term HIV infection and the difficulties the patients encountered while using the long-term care.

\section{Results}

\subsection{Socio-demographic characteristics of the cases}

A total of 10 respondents, male accounted for 8, aged between 58-76 year old (average age of 64 years). The sexual orientation of infected persons with five homosexual relations, two for the bisexual relationship, 3 is the opposite sex. Half of the respondents had a college degree or above. $80 \%$ of the respondents had religious beliefs and the time of infection was from 1 to 9 years (Table 1).

Table 1. The Characteristics of the Respondents table

\begin{tabular}{|c|c|c|c|c|c|c|c|}
\hline No. & Sexuality & Age & Education & Religion & Occupation & Infection risk factor & Year \\
\hline 1 & Male & 60 & College & None & Merchant & Sex with same sex & 6 year \\
\hline 2 & Female & 59 & $\begin{array}{c}\text { Senior high Vocational } \\
\text { school }\end{array}$ & Folk belief & Medical person & Sex with Opposite sex & 5 year \\
\hline 3 & Male & 62 & Master & Folk belief & $\begin{array}{l}\text { Medical } \\
\text { person }\end{array}$ & Sex with same sex & 6 year \\
\hline 4 & Male & 65 & High school & Catholicism & Merchant & Sex with same sex & 4 year \\
\hline 5 & Male & 67 & University & Folk belief & Retirement & Sex with bi sex & 3 year \\
\hline 6 & Male & 70 & College & Folk belief & Retirement & Sex with same sex & 4 year \\
\hline 7 & Male & 76 & High school & Christian & Retirement & Sex with same sex & 2 year \\
\hline 8 & Male & 63 & Primary school & None & None & Share needles & 2 year \\
\hline 9 & Female & 58 & $\begin{array}{l}\text { Senior high vocational } \\
\text { school }\end{array}$ & Christian & Civil Servant & Blood transfusion infection & 9 year \\
\hline 10 & Male & 61 & Primary school & Folk belief & Civil Servant & Sex with bi-sex & 7 year \\
\hline
\end{tabular}

\subsection{Long-term care needs of elderly infected people}

There are three different types of Long-term care services: institutional services, community-based services, and home-based services (Chen, 2013). The long-term care service types is roughly divided into two types: (1) the provision of relevant professional services such as nursing, rehabilitation and social work services; (2) providing accessory and environmental improvement services (Liou, 2015). The assessment of long-term care service is from five facets, including whether the service is user-friendly, called usability, whether the service is user-friendly, called accessibility, whether the service can link different resources, called persistency, whether the service meets the user's habit, is called acceptability, and whether the service can make the user reasonably bear, called the affordability (Lin \& Yeh, 2004; Jhuang, 2008).

This study found that long-term care needs of elder people and their caregivers were more complex due to the interaction between HIV infection and aging factors. The findings suggest that the difficulties of the infected person include (1) Diseases and health care tissues: including disease treatment, such as weakening of the body 
function; diseases caused by opportunistic infections; side effects of serving antiviral drug combination therapy; changes in body image; deals with the problem of exclusion by medical system personnel Situation and so on. (2) Social prejudice and discrimination: Due to the biased and discriminated of the society against elders and people living with HIV, the elderly infected people are under the dual pressures caused by the above sources. (3) The adjustment and reflection of psychology and identity: for example, a. strengthened sense of death (old and HIV infection have constructed in society closely related with death); b. alienation (Because of being excluded, the elderly infected easily feel alienated with the relevant community); c. self -condemnation (internalization of society's negative impression and evaluation on the old age and HIV infection); d. suicide and suicide attempts; e. drug abuse. (4) The adjustment of relationship: Such as the sense of guilty of the survivors; the reduction in interpersonal relationships; multiple losses (including facing the passed away of friends and partners, and friends of distance and exclusion). Moreover, the reduction of interpersonal relationships of the elderly infected persons has increased a certain degree of difficulty to seek resource or care from the interpersonal network (Syu \& Cai, 2009; Chen, 2009).

\subsection{The dilemma of the elderly infected persons in the existing long-term care system}

\subsubsection{The lack of suitable community-based long-term care services}

According to the plan of government policy, we hope that long-term care can be communityization, but the relevant manpower and services are still lacking. The support power of the infected respondents is mostly by themselves, not from their family members or friends, the study found out. Among them, the proportion of living alone up to 4 percent, these data response the relevant policy should not emphasize only on the importance of family care services. Otherwise, the infected ones without the companion and family members will be sacrifices under this policy thinking. Due to the lack of informal care system support, they will be in a disadvantageous position (Chen \& Lin, 2008).

\subsubsection{The rejection of the infected person from institutional long-term care services}

The results show that the elderly infected people are facing with the two challenges of discrimination and prejudice from the society when they want to use institutional long-term care services. One is the rejection of the caring institution to take care of the infected persons; the other is that infected persons are unable to pay for the cost of institutional long-term care services.

\subsubsection{The lack of financial resources for the use of institutional long-term care}

The results show that the respondents have more potential economic income problems; when the economic income is unstable, and the lack of financial support from relatives and friends. Elderly infected persons are still under the economic pressure of affording institutional long-term care services.

\subsubsection{The break between AIDS care and long-term care}

The results show that the planning direction of current long-term care system in Taiwan has failed in integration of chronic medical care, AIDS care and long-term care. Thus, it is unable to accord with the need of the users. Caregiver conversion is a kind of torture for the infected person, and cannot achieve the goal of maintaining or improving the physical and mental function of the users. The rupture between AIDS and long-term care brought the misunderstanding of the attitude of the long-term care agency to the infected person and the lack of relevant social resource may lead to the tendency of not applying the relevant services (Chen, 2008).

\subsubsection{Long-term care focus heavily on body function, neglect social psychological factors}

The study found that long-term care services are still concentrated in medical services or daily life activities, rather than dealing with psychological benefits of social issues. Respondents indicated that the current service still not meet the needs of infected people, the service is not easy to use. The relevant system has not been able to link different resources and provide appropriate services of the social psychological situation and habits of infected people.

\section{Conclusion}

Regarding service and social support needs, the need for legislation protecting the right of people living with HIV/AIDS was high. However in Taiwan, the law protects the right of every citizen including people living with HIV/AIDS. The overwhelming need to take such legislation might be due to a lack of knowledge of this law or the existence of some loopholes that have diminished the effectiveness AIDS patients or that the law may just protect severe case of violation of HIV/AIDS patients' rights (Lau \& Wong, 2001). About the psychosocial needs, the need for assistance for strenuous daily activities such as laundry, housecleaning, exercise and visiting relative and friends by people living with HIV/AIDS in the residential care facilities was probably due to the fact that 
most of the patients in residential care facilities were terminallyill AIDS patients. This is consistent with the findings of Smith et al. where the greatest completely unmet need of AIDS patients was doing strenuous tasks and activities (Smith \& Rapkin, 1995).

Overall the health care need was relatively low among the patients. This might be explained partly by the fact that a majority of the people living with HIV/ AIDS in Taiwan, like other citizens in the country, have national health insurance. Indeed the lack of insurance is associated with barriers to care (Golstein et al, 2005). The need for HAART and the treatment of opportunistic infections by patients in residential care facilities should be seen as an expression for the necessity to continue to receive these treatment from the national health insurance rather than a real lack of these medications. The high level of labs and test among the 3 groups of HIV/AIDS probably suggest their wish for more clinical counseling and information on HIV/ADS as mentioned above. Since there is no cure for the disease HIV/AIDS patients might be anxious about their health status and need to be reassured through counseling and other information. In term of health care needs with regard to access to care, patients in outpatients' clinic had almost no health care needs compare to those in residential care facilities and prisons. One explanation of this fact is the good quality of care they received in the outpatients' clinic. Another explanation is that most the patients in this setting had an employment and $88.1 \%$ of them had an average monthly income more than $\$$ NT 16,000 . The fear around confidentiality mentioned by the patients was certainly linked to the misconceptions about HIV/AIDS (Lee, Fu, \& Fleming, 2006; Lew, \&, Hsu, 2002). This is consistent with the finding of Sauka and Lie where concerns for privacy and the importance of confidentiality were stressed as a main prerequisite for trusting relationship with doctors and, therefore, for a successful counseling process (Sauka, \& Lie, 2000). Although stigma and discrimination tend to decrease in Taiwan, the early strategy of public education and prevention of HIV/AIDS was fear-based and therefore had caused fear and misconception about the disease in the general public and had created social stigma around HIV/AIDS (Hsiung, Tsai, Hung, \& Chen, 2001). Perceived health status was higher among outpatients clinic participants compared to those who stayed in residential care facilities. This might be related to the fact that most of the patients in residential care facilities were terminally ill AIDS patients and as expected had weaker physical and psychological health status.

Elderly patients with HIV infection and aging by two factors and virus infections have their special needs, but in the past the social environment of Taiwan for discrimination against those infected and not friendly, the long term care service needs of infected persons have not been valued and satisfied. With the increase of the elderly population in Taiwan, the long-term care service system has gradually been attached importance to in Taiwan. In the process of policy thinking and formulation, it is necessary for policy makers and caregivers to seriously consider and consider the needs of elderly infected people. The purpose of this study is to present the needs of elderly people living with HIV / AIDS in Taiwan, and to examine the shortcomings of the current long-term care system in Taiwan for the service of elderly infections, and to improve the existing systems and services (Lai, 2008).

\section{Acknowledgments}

This study was supported by Master Program of Long-Term Care in Aging, Kaohsiung Medical University, Taiwan. We would like to thank Professor Jian,Yi-Zuo for his help in editing the manuscript; Taiwan Love Hope Association, Kaohsiung Long-term Organization, Kaohsiung City Hospital for their help in recruiting people living with HIV/AIDS to participate in this study.

\section{References}

Chen, C.-H. (2013). An introduction of long-term care (5th ed.). Taichung, Taiwan: Huagena.

Chen, C.-W. (2008). The illness narratives of people living with AIDS (Unpublished master's thesis). Kaoshiung Medical University, Kaoshiung, Taiwan.

Chen, C.-W., \& Lin, C.-C. (2008). Applying the family adjustment and adaptation response model to care of an AIDS patient's family. Journal of Nursing Research, 55, 104-09. https://doi. 10.6224/JN.55.2.104

Chen, Y.-L. (2009). A study on social network and social adjustment among HIV-positive injection drug users (Unpublished master's thesis). National Chi-Nan University, Nantou, Taiwan.

Easterbrook, L. (2002). Move On From Community Care. London: Age Concern England.

Gelfand, D. E. (2006). The ageing network: programs and services (6th ed.). New York: Springer.

Goldstein, R. B., Rotheram-Borus, M. J., Johnson, M. O., Weinhardt, L. S., Remien, R. H., Lightfoot, M., Catz, S. L., Gore-Felton, C., Kirshenbaum, S., Morin, S. F., \& NIMH Healthy Living Trial Group. (2005). Insurance coverage, usual source of care, and receipt of clinically indicated care for comorbid conditions 
among adults living with human immunodeficiency virus. Med Care, 43(4), 401-10.

Gorman, E. M., \& Nelson, K. (2004). From a far place: Social and cultural considerations about HIV among midlife and older gay men. In G. Herdt \& B. de Vries (Eds.), Gay and lesbian aging: Research and future directions (pp. 73-93). New York: Springer.

Hsiung, P. C., Tsai, Y. F., Hung, C. C., \& Chen, M. Y. (2001). Intention of residents in internal medicine to care for patients infected with HIV at a university hospital in Taiwan. International Journal of STD \& AIDS, 12(9), 602-8. https://doi. 10.1258/0956462011923787

Hung, I.-C. (2008). The continuity care of quality of long term services for the elderly users (Unpublished master's thesis). Asia University, Taichung, Taiwan.

Jhuang, S.- M. (2008). The research of institutional long-term care service industry. Taipei, Taiwan: Somghuei.

Lai, Y.-Y. (2008). Narratives of intimate relationship among women living with HIV (Unpublished master's thesis). National Cheng Kung University, Tainan, Taiwan.

Lau, J. T., \& Wong, W. S. (2001). AIDS-related discrimination in the workplace - the results of two evaluative surveys carried out during a three-year period in Hong Kong. AIDS Care, 13(4), 433-40. https://doi.10.1080/09540120120057969

Lee, T. S., Fu, L. A., \& Fleming, P. (2006). Using focus groups to investigate the educational needs of female injecting heroin users in Taiwan in relation to HIV/AIDS prevention. Health Educ Res, 21(1),55-65. https://doi. 10.1093/her/cyh041

Lew-Ting C. Y., \& Hsu, M. L. (2002). Pattern of responses to HIV transmission questions: rethinking HIV knowledge and its relevance to AIDS prejudice. AIDS Care, 14(4), 549-57. https://doi.10.1080/0954012020 8629673

Lin, L.-F., \& Yeh, L.-L. (2004). To explore the practice of the integration and management mechanism of long-term care resources in Taiwan. Community Development Quarterly, 106, 106-14.

Liou, S.-J. (2015). Long-term care. Taipei, Taiwan: Huasing.

Lou, Y. J., Wu, P. Y., Liou, M. J., \& Jhang, S.-C. (2008). Risk factors of delayed HIV diagnosis in Taiwanese men who have sex with men. Taiwan Journal of Epidemic Reporting, 24(11), 813-25.

Sauka, M., \& Lie, G. T. (2000). Confidentiality and disclosure of HIV infection: HIV-positive persons' experience with HIV testing and coping with HIV infection in Latvia. AIDS Care, 12(6), 737-43. https://doi. $10.1080 / 09540120020014282$

Smith M. Y., \& Rapkin, B. D. (1995). Unmet needs for help among persons with AIDS. AIDS Care, 7, 353-63. https://doi. 10.1080/09540129550126560

Syu, S.-J., \& Cai, C.-M. (2009). Promote resettlement agencies to accommodate AIDS patients. Community Development Quarterly, 127, 225-33.

Tsai, C.-M., \& Hsu, S.-C. (2009). The exploration of the dilemma relationship between HIV serodiscordant gay couples. NTU Social Work Review, 19, 1-40. https://doi. 10.6171/ntuswr2009.19.01

Twu, S. J., Huang, Y. F., Lai, A. C., Ming, N., \& Su, I. J. (2004). Update and projection on HIV/AIDS in Taiwan. AIDS Education and Prevention, 16, 53-63.

Wu, S.-C. (2005). Population aging and long-term care policy. National Policy Quarterly, 4, 5-24.

Yin, Z.-C., \& Li, Y.-J. (2002). To develop the long term care model for AIDS patients in Taiwan. Taipei veterans general hospital, Taiwan.

\section{Copyrights}

Copyright for this article is retained by the author(s), with first publication rights granted to the journal.

This is an open-access article distributed under the terms and conditions of the Creative Commons Attribution license (http://creativecommons.org/licenses/by/4.0/). 